\title{
Collaborative Intelligence in Smart Cities: A Systematic Review
}

\author{
Viviani Kwecko', Silvia S. da C. Botelho² \\ ${ }^{1}$ Federal Institute of Science and Technology Education of Rio Grande do Sul-IFRS, Rio Grande, Brazil \\ ${ }^{2}$ Federal University of Rio Grande-FURG, Rio Grande, Brazil \\ Email: viviani.kwecko@riogrande.ifrs.edu.br
}

How to cite this paper: Kwecko, V. and da C. Botelho, S.S. (2018) Collaborative Intelligence in Smart Cities: A Systematic Review. Social Networking, 7, 181-195. https://doi.org/10.4236/sn.2018.73015

Received: May 14, 2018

Accepted: July 22, 2018

Published: July 25, 2018

Copyright $\odot 2018$ by authors and Scientific Research Publishing Inc. This work is licensed under the Creative Commons Attribution International License (CC BY 4.0).

http://creativecommons.org/licenses/by/4.0/

\begin{abstract}
The objective of this research is to present a systematic analysis, in which we seek to identify the concepts of intelligent city, with the intention of recognizing the nature of this intelligence before the participation of the population. Therefore, the research associates concepts as smart cities, citizen participation and social web, identifying publications between 2012 and the first quarter of 2018 and questioning what the intelligent city is and how this concept is able to (re)organize the learning processes of the territory from the informal dynamics of the contemporary city. The qualitative analysis of the documents revealed an innumerable of definitions and related terms: smart, intelligent, ubiquitous, digital, knowledge, sustainable, crowd sourcing, innovative; structured in three types of approaches: technological focus, focus on human resources and focus on citizen-related governance from the following domains: media convergence, public and regulatory information policies, infrastructure management, real-time data mining and extraction, geographic information system, crowd computing, smart cities education, and social monitoring and control. In spite of the access to a great amount of data, we verify that the concept of intelligent city is referenced by a significant number of researches, but, in smaller number, works that present models of construction of a collective intelligence for the city. From this perspective, we identified the need to recognize technological education interventions for communication between individuals and the city. Because we believe that only through the implementation and management of techno-educommunication ecosystems will be able to promote a culture of participation.
\end{abstract}

\section{Keywords}

Territorial Learning, Non-Formal Education, Technological Artifacts, Informal Dynamics, Citizen Participation 


\section{Introduction}

The technological development which characterizes the last decades of the occidental societies' economical progress has been transforming the city, once in industrial, in a city of information and knowledge. The emerging technologies come as facilities in the interaction process between the development agents in the territory and the virtual knowledge systems, of which the concept of intelligent territory emerges. According to the European Union [1], a Smart City represents systems of people interacting and using energy, materials and services to catalyze economic development and quality of life. These interaction flows are considered to be intelligent because they make strategic use of infrastructure and information and communication services to meet the social, educational and economic needs of society. The overlapping of an apparently invisible network of interactions and information, floating with the historically solid and strong domain of our cities and the sensory condition of our experience, captured our daily actions.

The expression "Smart City" evokes this gathering of phenomena that acquires an intangible dimension in its potential of connection between events and situations, people and places, technologies and learning, creating an emergency of a knowledge-based interaction.

Researchers from the Humanities and Technological areas have been attracted by this new information paradigm that is based on a new culture with a clear technological acceleration. With regard to the humanities, it provides some points of apprehension about the new interaction's arrangements between the humanities, information sciences and digital technologies: 1) use of information technologies for the production of scientific knowledge that analyzes processes social, cultural, and political issues related to the mediation of information and communication technologies; 2) science based on simulation procedures, called "cyber sciences" or "silicon sciences" [2]; 3) interdisciplinary scientific field between $\mathrm{Na}$ nosciences, Biotechnologies, Informatics and Cognitive Sciences-N.B.I.C.; and as 4) a organized and explanatory element of the communicational processes in living beings or machines, according to the initial propositions of [3].

Aware of this growing interest and the multidisciplinary nature of the topic, we seek to delineate in the State of Knowledge [4] some reference frameworks that assume the role of guide in the identification and systematization of a technological education resulting from the dialogue between the citizen and the city of information and knowledge.

In this way, this research presents a systematic analysis about existing works, in which we seek to: 1) identify the concepts on smart cities which have been discussed in the literature; 2) recognize the nature of the city's intelligence before the population participation; and 3) detecting the emerging themes which reveals how the knowledge and its spread between individuals and artifacts represent a collective intelligence [4].

The importance of this critical reflection about the proposed inquiries is justi- 
fied in face of the great amount of research that approaches the concept of smart city. However, we find in a smaller number of works that present models of construction of a collective intelligence for the city that consider as much the data coming from the Internet of things as the existential statements of the population. We problematize if these researches, when proposing instruments or studies that verify the systematic transformation of the immense volume of data into knowledge, do so considering the local knowledge of the population to promote an intelligence for the city. The relevance of this research is to identify the current forms of citizen participation in the reflexive construction of a collective intelligence.

The innovative character of the theme also needs to recognize technological education interventions for communication between individuals and the city. Because we believe that only through the implementation and management of techno-educommunication ecosystems, we will be able to promote a culture of participation and innovation, transforming community knowledge into a priority guideline for the elaboration of projects that benefit the community.

Thus, we believe that the emerging design of the published research will provide us security about sources of study, pointing out topics for further exploration, and also making us understand meaningful silences about collective intelligence processes.

The remaining of this paper is organized as follows. In Section 2 the methodology behind the research associates concepts as smart cities, citizen participation and social web, identifying publications that question which the intelligent city is and how this concept is able to (re)organize the learning processes of the territory from the informal dynamics of the contemporary city is detailed. In Section 3 the results of the qualitative evaluation are given and discussed. Finally, in Section 4 the conclusion and perspectives of future work are presented.

\section{Methodology}

The literature review consisted of three phases. Aware of the multidisciplinary nature of the theme, the first phase sought to recover a broad set of documents. In order to achieve this goal, an advanced search query was conducted on the Science Direct [5], Google Scholar [6], and IEEE Xplore [7] databases. The selection of these searching tools represents, in this work, the approximation between a search base that integrates thousands of articles related and continuously reviewed by an editorial board and a rescue base throughout the web, which main characteristic is the relationship with the user due to its simplicity, speed and breadth of information. Science Direct is a database of Elsevier publisher that indexes approximately 250,000 articles, with open access, covering areas such as health, engineering, social sciences and computer science, among others.

Published by the Institute of Electrical and Electronic Engineers, the IEEE Xplore digital library is a powerful resource for discovery of and access to scientific and technical content. The content in IEEE Xplore comprises approximately 
195 journals, 1400 conference proceedings; 5100 technical standards; 2000 books; and 400 educational courses that bring together the most cited publications in the world in electrical engineering, computer science and electronics.

The third database surveyed involves approximately 160,000 conferences and 8500 journals in approximately 150 knowledge areas, being considered one of the most used databases in systematic reviews. Researchers question the quantity and quality of what is saved in Google Scholar compared to other scientific databases; however, we emphasize that this massive communication is one of the central focuses that justify our research.

In addition, the search was performed without limiting the field of knowledge of the periodicals in which the article could be published. To do so, the keyword "Smart City" has been entered to be searched in the "all text", "theme", "title", "keywords" and "summary" options in each of the selected databases. There were a total of 58 on Science Direct, 265 on the IEEE Xplore, and 522 publications in Google Scholar among articles, books, editorials, journals, theses and technical reports.

The second phase consisted of our research field framework, through a new discussion associated with the concept of smart cities with the expressions "smart citizen" and "web social" on Science Direct; "smart citizen", "web social", "social web" and "citizen participation" on IEEE Xplore; and "citizen participation" and "social web" on Google Scholar.

It is important to note the need to adapt the nomenclature during the search process, since the terms "citizen participation", "web social" and "smart citizen" were considered as synonyms and no return occurred without this consideration.

Another aspect to be considered was the temporality between 2012 and the first quarter of 2018, justified by the fact that it represents the period of greatest number of publications in the area indicated by the first phase of the research. Subsequently, articles that highlighted the relevance in the use of technological artifacts in the midst of the digital social networks as mediating tools of citizen participation in the development of structural proposals of intelligence for cities more human were selected based on the abstracts. It occurred, respectively, the total of 3 on Science Direct, 5 on IEEE Xplore and 131 publications on Google Scholar, among articles, books, editorials, journals, theses and technical reports.

After this selection stage, the introductory section was read and an overview of the article structure was checked and categorized. The articles of specific technical nature about the city's intelligence were eliminated from the sample, since they did not contemplate actions of effective citizen participation. In addition, double counting of articles was avoided by counting only the articles that were different in the databases, as well as all the inclusion and exclusion criteria presented in Table 1.

This resulted in a corpus of 71 documents dealing with a variety of different aspects of citizen participation in the city's intelligence. As for the source of the publication, (thirty) articles were published in magazines, (ten) books, (three) 
chapters in books, (two) unpublished research reports, (eight) newspapers, (eight) conferences and (ten) postgraduate dissertations. This production covers a wide variety of magazines and conferences.

The third phase consisted of a detailed reading of the works selected in the previous phase in order to select only the relevant articles to our research quesanalysis for each of the identified domains. Literature reviews were removed from the sample because they did not present a new contribution to the domains. This resulted in a corpus of 20 papers dealing with a variety of different aspects of citizen participation in the city's intelligence.

\section{Results and Discussion}

As a result of the first step, we obtained a total of 2733 publications on Science Direct, 8400 publications on IEEE Xplore and 19,600 articles on Google Scholar viewed in its annual distribution of publications and sources in Figure 1.

We emphasize that a good part of the indicated studies' contributions comes from a very recent temporality of production, since only those published in the period between 2012 and 2018 have gone from three (3) digits. However, there is a growing beginning of this reflexive movement on the theme from 2013, when this number reaches more than 500 publications on both platforms. Nonetheless, in the search to contextualize this observation it is necessary to recognize the

Table 1. Critérios de inclusão e exclusão de artigos.

\begin{tabular}{cc}
\hline INCLUSÃO & EXCLUSÃO \\
\hline $\begin{array}{c}\text { Publications in the period from } 2012 \text { to } 2018 \\
\text { Present the concept of smart cities } \\
\text { Using citizen participation as the focus of } \\
\text { intelligence for the city }\end{array}$ & $\begin{array}{c}\text { Articles outside the context of the study } \\
\text { Works that do not contemplate citizen } \\
\text { participation }\end{array}$ \\
\hline
\end{tabular}

Source: Research/Author.

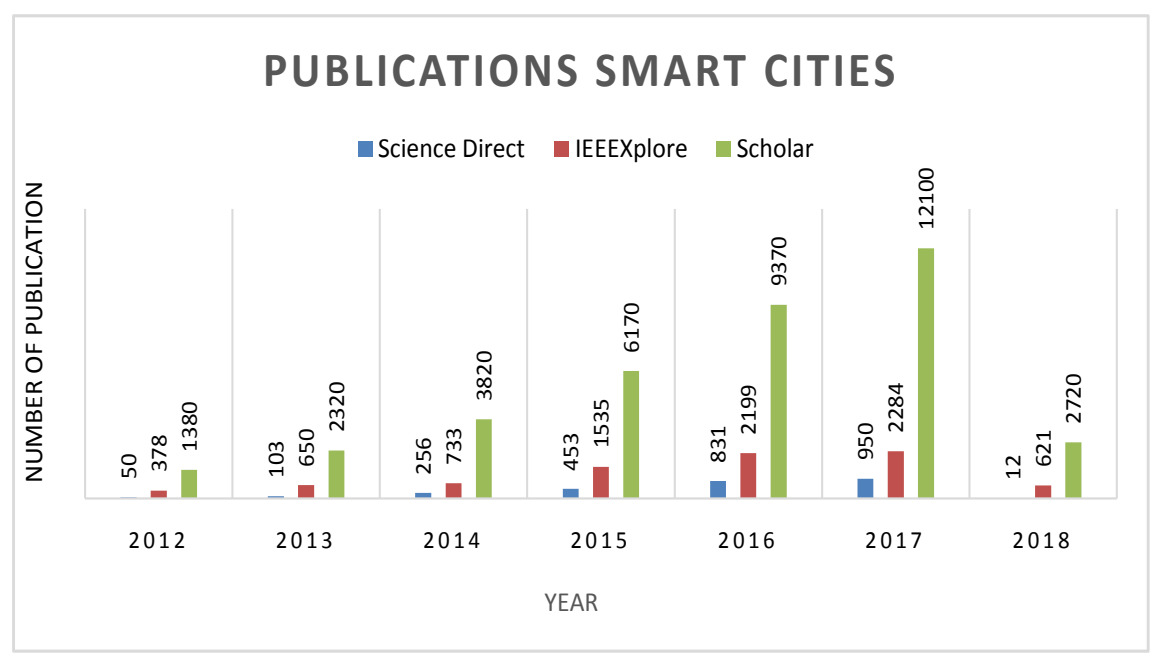

Figure 1. Annual distribution of articles published on "smart cities". Source: Research/ Author. 
historicity of technological development as well as the development of the appropriation process by individuals.

This temporality was presented by [8] from the design of three eras for the digital age: the era of the microcomputer; the era of the World Wide Web and the era of the semantic Web. For the author, the first era is composed of two phases: the phase from 1980 to 1990, in which the desktop and its file systems, e-mail, servers, databases are found; and another that runs from 1990 to 2000 and includes Web 1.0 and its add-ins: HTTP, HTML, teamwork, intranets, Java, portals.

The second era is considered from 2000 to 2010 when the $W W W$ era evolved with Web 2.0, social networks, blogs and wikis, XML/J2EE. In the approach of the third era-the Semantic Web-from 2010 and estimated until 2020, begins to appear the cloud computing, the Web as a database, intelligent personal agents and the Rule Interchange Linked Data (exchange format between languages and data). This third and last semantic era coincides with the relevance of research on smart cities. Lafuente [8] considers the purpose of the semantic sphere to present a new system of codification of meanings, by which operations on the meaning of a digital memory could become transparent, interoperable and computable. For the author, we do not know "yet" how to systematically transform the immense volume of data into knowledge that effectively represents a reflective resource for our collective intelligences.

Lévy's [9] observation is corroborated by the inexpressive quantity of publications, visualized in their annual distribution in Figure 2, which highlights some relevance in the application of citizen participation for the reflexive construction of a collective intelligence for the city. We found a total of 139 publications over a period of seven years, after considering the relevance of the citations of each article and assuming the task of global analysis of the content of each publication.

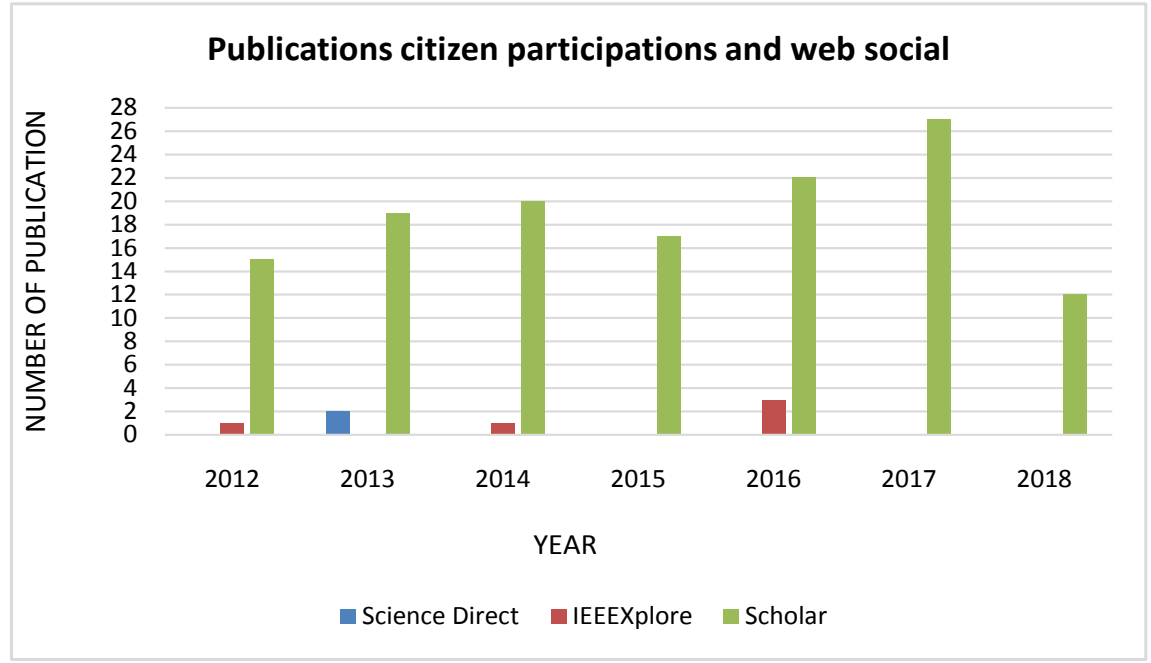

Figure 2. Annual distribution of published articles on "citizen participation" and "social web". Source: research/authors. 
This fact demonstrates the innovative nature of the theme, but it also indicates the distance that we are facing from the production of collective knowledge from the common digital data.

During the qualitative analysis of the documents we verified a myriad of definitions and terms related to the concept of intelligence of the city, being: smart, intelligent, ubiquitous, digital, knowledge, sustainable, crowd sourcing, innovative. Regarding the treatment of the theme, we found three different types of approaches: 1) publications presenting the concept of smart cities associated with cities using intelligent technologies (technology approach), 2) publications presenting the concept of smart cities as constituted cities by intelligent communities (a focus on human resources) and 3) publications that presented the concept of smart cities as cities with citizen participation (focus on governance systems). Some of the documents analyzed are clearly acceptable into one of these categories, while others presented definitions of hybrid approaches.

From the point of view of the international literature, these aspects are related to the existence of economic and social development strategies, based on: 1) an offer of modern infrastructure, especially in the pervasive use of Information and Communication Technologies (ICTs) [10]; 2) an improvement in the competitiveness and alignment of the knowledge economy, with a focus on the creation of environments conducive to entrepreneurship, creativity and innovation [11] [12] [13]; and 3) a highly socially and environmentally sustainable lifestyle [14] [15].

When we verify the relation of these approaches of the city's intelligence with the participation of the citizen, we tried to map the following strategies pointed by each publication as: what technological approach was used to contemplate the participation of the population; if and how information was extracted from digital data common to the population knowledge (collective intelligence); and which strategies of public management of knowledge were pointed out.

As for the methodological-technological approach, the studies mention the use of web analysis, data mining, neural networks, deep learning and machine learning to establish sources, actors, activities, networks and communication strategies with the population.

For the qualitative observation of the obtained results, we inductively developed categories for the different dimensions, which were applied to the same grouping of publications. The resulting dataset was analyzed for variation and similarities to map the conceptual fragmentation of approaches that were gathered in eight domains: 1) media convergence and citizen participation, 2) public and regulatory information policies, 3) infrastructure management, 4) real-time data mining and extraction, 5) geographic information system, 6) crowd computing, 7) smart cities education, and 8) social monitoring and control. As verified in the previous criteria, some articles clearly compose one of these categories while others have composite definitions, and these dualities were observed and recorded during this grouping phase. The information resulting from this second stage of analysis is presented in Table 2. 
Table 2. Analysis of the city's intelligence focuses on citizen participation.

\begin{tabular}{|c|c|c|c|c|c|c|c|}
\hline \multirow{2}{*}{ Indicators } & \multicolumn{6}{|c|}{ Period } & \multirow[b]{2}{*}{2018} \\
\hline & 2012 & 2013 & 2014 & 2015 & 2016 & 2017 & \\
\hline $\begin{array}{l}\text { Media convergence and } \\
\text { citizen participation }\end{array}$ & 7 & 6 & 7 & 6 & 5 & 4 & 1 \\
\hline $\begin{array}{l}\text { Public and regulatory } \\
\text { information policies }\end{array}$ & 2 & 3 & 2 & 4 & 3 & 3 & 1 \\
\hline $\begin{array}{c}\text { Infrastructure } \\
\text { management }\end{array}$ & 3 & 2 & 5 & 2 & 4 & 4 & 1 \\
\hline $\begin{array}{l}\text { Extraction and mining of } \\
\text { data in real time }\end{array}$ & 1 & 4 & 4 & 2 & 3 & 5 & 3 \\
\hline $\begin{array}{l}\text { Geographicalinformation } \\
\text { system }\end{array}$ & 2 & 3 & 0 & 1 & 4 & 4 & 1 \\
\hline Crowd computing & 1 & 0 & 2 & 0 & 3 & 3 & 2 \\
\hline $\begin{array}{l}\text { Education for smart } \\
\text { cities }\end{array}$ & 0 & 0 & 0 & 0 & 2 & 2 & 1 \\
\hline $\begin{array}{l}\text { Monitoring and social } \\
\text { control }\end{array}$ & 0 & 3 & 1 & 2 & 2 & 2 & 1 \\
\hline Total & 16 & 21 & 21 & 17 & 26 & 27 & 11 \\
\hline
\end{tabular}

Source: Research/Author.

The study shows that the publications of the period between 2012 and 2018 do not present an explicit perspective on the approach of citizen participation in the cities' intelligence, demonstrating a dispersion of research on the subject. It is important to observe that the categories of higher incidence are demarcated by processes of transmigration and regulation of information. Within this context, the concept of the transmissible narrative proposed by [16] appears as a strategy that understands and adapts to the moment of cultural revolution provided by digital media. The author's vision is a narrative that is complemented by using a series of different platforms, allowing the public an interaction, with what is produced, allowing the community to actively give an opinion on the creation of what they are consuming. The same happens with the category of public and regulatory information policies, because the main actors in the regulatory process in Brazil are the regulatory agencies, the Executive, the Congress (House, Senate and Commissions), the Judiciary, entrepreneurs, consumers and other interest groups.

During the analysis of the publications it was possible to verify that in the first category and in the second, the participation of the company is based on the decisions already taken, being the most important manifestation center of the citizen or the user the evaluation process.

Of the other categories of interest organized by this research, we pondered the thematic of the extraction and mining of data of the city in real time. This choice is justified as it represents a technological basis for obtaining data and information to be transformed into effective citizen participation in collective intelligence. Collecting data on populations has, throughout history, represented an 
important political element of various government technologies [17]. From the term censor, dated in Roman antiquity, to the current information and communication systems of cyber culture, the daily monitoring of individuals' actions represents a technology of social control. But the scenario today is quite different and we see exponentially increasing a mass of data to circulate through a decentralized network and with different purposes, from advertising to crime control, from health promotion to entertainment.

Data mining is the process of obtaining and interpreting information, through predictive models, applied to large databases. It is one of the steps in the Knowledge Discovery in Databases (KDD) process, which consists of a set of computational tools and techniques that implement learning or classification algorithms. According to Han, Kamber and Pei (2012), data mining is an interdisciplinary field that uses concepts from databases, statistics, machine learning, artificial intelligence, pattern recognition, data storage systems, information recovery, visualization, high performance computing algorithms and various other application domains.

Santos (2009) [18], Han, Kamber and Pei (2012) [19], highlight that the main approaches to data mining on the web are structured using the following approaches: 1) Structure Mining (Web Structure Mining) organization and cross-referencing of links, in particular through hyperlinks; 2) Use Mining (Web Usage Mining) Generation of standards with the use of user navigation logs; 3) Content Mining (Web Content Mining), the knowledge derives from the content of the documents and their metadata; (description, information on authors, keywords, etc.).

The analysis made in the selected articles set was organized from four cases of Use Mining: 1) to monitor specific issues in normal circumstances; 2) to monitor the occurrence of specific events; 3 ) monitor tendencies of candidates and elections; 4) monitoring social-cultural or consumer trends. In Table 3 we present the 20 selected publications identifying the classifications from their use case.

Any set of data only makes sense if it is analyzed and classified in order to produce knowledge about the reality or the individuals to whom it refers. Considering this moment on, the meeting between the potentialities of the technological artifacts of data mining and the processes of a social education will build their interfaces.

The aspects of a city are presented as patterns, which at the same time order and objectify the multiplicity of human coexistence, legitimizing ways of experiencing, inhabiting or governing it. But what socio-educational order is involved in this knowledge generated by a data mining? Are we repeating the traditional means of extracting norms and averages from social and human diversity, since it is about determining standards and regularities? We do not think so. The norm and the average are only a modern way of producing standard and conceiving of nature and social laws. It is not a question of extracting a (average) regularity of the population's perception of a certain aspect of the city and of 
Table 3. Identification of articles presenting data mining as a tool to analyze citizen participation.

\begin{tabular}{|c|c|}
\hline Article & Use Case \\
\hline $\begin{array}{l}\text { Smart government: A new adjective to government } \\
\text { Transformation or a trick? [20] }\end{array}$ & $\begin{array}{l}\text { Monitor specific under normal } \\
\text { circumstances }\end{array}$ \\
\hline $\begin{array}{l}\text { Value creation and barriers in the commercial use of open } \\
\text { government data [20] }\end{array}$ & Monitor the occurrence of events \\
\hline $\begin{array}{c}\text { The next wave of innovation-Review of smart cities } \\
\text { intelligent operation systems, computers in human } \\
\text { behavior [21] }\end{array}$ & $\begin{array}{l}\text { Monitor specific under } \\
\text { normal circumstances }\end{array}$ \\
\hline $\begin{array}{l}\text { Chapter 13-WoX: Model-driven development of web of } \\
\text { things applications, in managing the web of things [22] }\end{array}$ & $\begin{array}{l}\text { Monitors tendencies of } \\
\text { candidates and Elections }\end{array}$ \\
\hline $\begin{array}{l}\text { Digital Europe 2030: Designing scenarios for ICT in future } \\
\text { governance and policy making [23] }\end{array}$ & $\begin{array}{l}\text { Monitors social-cultural } \\
\text { or consumer trends }\end{array}$ \\
\hline $\begin{array}{l}\text { Impact of social media on the behavior of Tunisian voters: } \\
\qquad 2014 \text { elections }[24]\end{array}$ & $\begin{array}{l}\text { Monitor specific under } \\
\text { normal circumstances }\end{array}$ \\
\hline $\begin{array}{l}\text { SOCIA: Linked open data of context behind local } \\
\text { concerns for supporting public participation [25] }\end{array}$ & $\begin{array}{l}\text { Monitors social-cultural } \\
\text { or consumer trends }\end{array}$ \\
\hline Chapter 5-Big data, in managing online risk [26] & $\begin{array}{l}\text { Monitors social-cultural } \\
\text { or consumer trends }\end{array}$ \\
\hline $\begin{array}{l}\text { Urban computing in the wild: A survey on large scale } \\
\text { participation and citizen engagement with } \\
\text { ubiquitous computing, cyber physical } \\
\text { systems, and Internet of things [27] }\end{array}$ & $\begin{array}{l}\text { Monitor specific under } \\
\text { normal circumstances }\end{array}$ \\
\hline $\begin{array}{c}\text { Social data mining and knowledge flows between } \\
\text { government and its citizenry in crisis and } \\
\text { normal situations [28] }\end{array}$ & $\begin{array}{l}\text { Monitors social-cultural } \\
\text { or consumer trends }\end{array}$ \\
\hline $\begin{array}{c}\text { Real-time multimedia policy analysis of using } \\
\text { video and audio recognition from radio, TV, and } \\
\text { user-generated content [29] }\end{array}$ & $\begin{array}{l}\text { Monitors social-cultural } \\
\text { or consumer trends }\end{array}$ \\
\hline $\begin{array}{l}\text { Casa Kolacho: Participación ciudadana y narrativas } \\
\text { transmedia en la comuna } 13 \text { de medellín_Colombia [30] }\end{array}$ & $\begin{array}{l}\text { Monitors social-cultural } \\
\text { or consumer trends }\end{array}$ \\
\hline $\begin{array}{l}\text { Social media enactment study for the } \\
\text { district of north Vancouver [31] }\end{array}$ & $\begin{array}{l}\text { Monitors social-cultural } \\
\text { or consumer trends }\end{array}$ \\
\hline $\begin{array}{l}\text { Crowd sourcing for transit-oriented planning } \\
\text { projects: A case study of "interactive Somerville" [32] }\end{array}$ & $\begin{array}{l}\text { Monitors social-cultural } \\
\text { or consumer trends }\end{array}$ \\
\hline $\begin{array}{l}\text { Mobile 311: A framework for } 311 \text { services with } \\
\text { smart technology [33] }\end{array}$ & $\begin{array}{l}\text { Monitors social-cultural } \\
\text { or consumer trends }\end{array}$ \\
\hline $\begin{array}{l}\text { Open government and citizen participation in } \\
\text { law enforcement via crowd mapping [34] }\end{array}$ & $\begin{array}{l}\text { Monitor specific under } \\
\text { normal circumstances }\end{array}$ \\
\hline $\begin{array}{l}\text { Delivering public value: synergistic } \\
\text { integration via Gov } 2.0[35]\end{array}$ & $\begin{array}{l}\text { Monitor specific under } \\
\text { normal circumstances }\end{array}$ \\
\hline $\begin{array}{l}\text { Towards a typology of social news apps from a crowd } \\
\text { computing perspective [36] }\end{array}$ & $\begin{array}{l}\text { Monitors social-cultural } \\
\text { or consumer trends }\end{array}$ \\
\hline $\begin{array}{l}\text { Online media in a context of proximity in Galicia and } \\
\text { Portugal and its presence on the social networks [37] }\end{array}$ & $\begin{array}{l}\text { Monitors social-cultural } \\
\text { or consumer trends }\end{array}$ \\
\hline $\begin{array}{l}\text { A mobile based technology platform for citizen } \\
\text { engagement in Malawi [38] }\end{array}$ & $\begin{array}{l}\text { Monitors social-cultural } \\
\text { or consumer trends }\end{array}$ \\
\hline
\end{tabular}

Source: Research/Author. 
transforming data into a regulation to be followed as a norm or as a rule. The observation of the different dimensions which constitute a city embody multiple micro-regularities among innumerable heterogeneous variables and do not present themselves as regulations. So when we use data mining as an artifact for social listening, we are allowed to identify who is the smart city and how the intelligence of the city learns from collective intelligences. An intelligent city must have the capacity to integrate systems of collective intelligence, aiming to confront local problems; produce public values, with focus and elaboration on co-participation, as an instrument capable of providing knowledge and structuring learning for a community project.

In order to detail a smart city, one of the most applied indexes is the European Smart Cities (2016). It is a methodology that describes intelligence through six characteristics (intelligent economy, intelligent people, intelligent governance, intelligent mobility, intelligent environment, intelligent life), 31 factors and 74 indicators. In Brazil, Urban Systems [39] presents the Connected Smart Cities Ranking, which considers the 11 axes (mobility, urbanism, environment, energy, technology and innovation, economy, education, health, safety, entrepreneurship and governance) and 73 indicators.

Other initiatives have been considered, such as Iese Cities in Motion (Iese Business School; University of Navarra, 2014); in Brazil [40], the project "Brazil 2030: Intelligent and Human Cities", coordinated by the Brazilian Network of Intelligent and Human Cities in partnership with the National Front of Mayors, which considers the verification of 4 axes (Governance and Architecture, Urbanism and Anthropology, Technology and Security) and 205 indicators; and the studies of the Brazilian Afonso et al. (2003) proposes, in addition to the indicators, the constitution of a maturity index for smart cities.

The Brazilian Smart Cities Maturity Model (BR-SCMM) is elaborated by the availability of data in public domains on the Brazilian municipalities, associated with the capacity of comparison of these with surveys conducted in other cities of the world (Afonso et al., 2013). Despite the proposed standard to take into account the international indexes for city intelligence, this model is still under development, having its first version addressing only Education, Health and Water.

In spite of this limitation, the authors emphasize the ability of these indicators to influence, directly and indirectly, several other domains of a city, considering the proportionality between the increase in levels of development and the investments in the area.

Br-SCMM considers in its composition the following performances: the educational dimension is measured in its quality, by raising the illiteracy rate, the statistics of dropout in basic education, besides the grades obtained in the Index of Development of Basic Education (IDEB) and the percentage of coverage of the service to the population of school age; the Health Index is composed of indicators of mortality, risk factors coverage of basic health care, incidence of 
chronic diseases over the population and the resources available for services; already the indices for the water gather data of the percentage of households served by public water supply network of the municipalities.

However, we realize that these approaches to city intelligence analysis do not consider in their scope the factors associated with the construction of meanings by the population about these same indicators.

Thus, the concepts of city intelligence greatly limit the potential of technological elements in the social context, since in this perspective the technology ends up being used only to model a ranking of capacity for cities. For Levy (2007), this intelligence is in constant process of construction and all knowledge must be valued. This understanding is essential for the valorization of social listening and cultural knowledge. And the main challenge is to insert the intelligence of the city in the context of informal education. Shifting the emphasis of a quantitative ranking to recognize and develop processes of community empowerment.

The aspects of a city are the micro-regularities of intelligence niches. In this perspective, Distributed Cognition seems adequate for understanding how Collective Intelligence [41] manifests at this systemic level, through the representation of knowledge and its propagation between individuals and artifacts [42].

From this approach, Data Science becomes a powerful tool capable of revealing the processes through which a shared cognition emerges among the members of a social group. We believe that through interaction, individuals establish cognitive niches [43], which, by involving a set of representations of internal (memory, language) and external (material and/or environmental) structures of individuals, are able to assume historical-temporal, so that previous events transform the nature of the present. Although the aspects are interindividual patterns of similarity, they do not claim to be social standards, but rather as potentialities of the most varied types of community life perception. Taxonomy and knowledge do not reveal a set of characteristics intrinsic to the city, but factors perceptions which constitute certain circumstances.

\section{Conclusions}

It is important to emphasize that our research movement chooses a trajectory initiated by the anthropological concept of city intelligence, to enable the technological approach to emerge from the relationship between city and citizen. Thus, the opportunity and benefits of social opinion monitoring represent an important tool for mining and data analysis that enables the structuring of collective intelligence statements. However, monitoring cannot and should not be perceived by the population as an invasive act in which the only intention is to use the data for the improvement of persuasive market processes. In order to do so, it is necessary to approximate theories of data analysis to the concepts defended by Hutchins (2000), for whom human cognition is distributed in a system formed by the individual in interaction with social, cultural and technological artefacts in a given environment. According to the author's considerations, 
these artifacts represent tools that carry cognitive processes, since they consist of devices used by humans to perform a certain activity, being able to improve the cognition and performance of the person who uses it [43] [44].

By recognizing these clues of social action from these numbers set, they expose the existence of a habit of users interacting with the social through the production and sharing of information in the midst of digital social networks. Despite this, this large amount of data is not being transformed into instruments of collective intelligence construction, since it requires interventions of a technological education for communication. Only when we transform community opinion into a priority guideline for the development of projects that benefit the community, from the implementation and management of techno-educational ecosystems, we will be able to promote the culture of participation and innovation.

Thus, as future work, we propose: (a) a qualitative analysis of the non-linear information systems that emerge from communities of interest, identifying the nature, structure and dynamics of these data; (b) a case study in which it is proposed to recover data and contents through the application of a system of opinion processing capable of extracting, processing and summarizing large volumes of public data in a modeling elaborated by the research group; (c) proposing a statistical analysis to obtain conceptual maps of smart cities indicators.

\section{Acknowledgements}

The authors would like to thank the following organs: Federal University of Rio Grande, Federal Institute of Science and Technology Education of Rio Grande do Sul, National Council for Scientific and Technological Development-CNPq, and thank Personal Improvement Coordination of Higher Education-Capes and CNPq by aid grants to students.

\section{References}

[1] Manville, C., Cochrane, G., Cave, J., Millard, J., Pederson, J.K., Thaarup, R.K., Kotterink, B., et al. (2014) Mapping Smart Cities in the EU.

[2] Martins, H. (2006) Dilemas da República Tecnológica. Análise Social, 181, 959-979.

[3] Wiener, N. (1948) Cybernetics: Control and Communication in the Animal and the Machine. John Wiley \& Sons, New York, 194.

[4] Fernandes, C.M.B. and Morosini, M.C. (2014) Estado do Conhecimento: Conceitos, Finalidades e Interlocuções. Educação Por Escrito, 5.

[5] Science Direct.

[6] Google Scholar. https://scholar.google.com.br/

[7] IEEE Xplore. https://ieeexplore.ieee.org/Xplore/home.jsp

[8] Lafuente, F. (2011) A era do raciocínio artificial. HSM Management, 86, 80-86.

[9] Lévy, P. (2014) A Esfera Semântica: Tomo 1-Computação, Cognição e Economia da Informação. Annablume Editora, São Paulo.

[10] Steventon, A. and Wright, S. (2010) Intelligent Spaces: The Application of Pervasive 
ICT. Springer, Berlin.

[11] Florida, R. (2004) The Rise of the Creative Class and How It's Transforming Work, Leisure, Community and Everyday Life (Paperback).

[12] Florida, R. (2005) Cities and the Creative Class. Routledge, Abingdon.

[13] Komninos, N. (2009) Intelligent Cities: Towards Interactive and Global Innovation Environments. International Journal of Innovation and Regional Development, 1 , 337-355. https://doi.org/10.1504/IJIRD.2009.022726

[14] Bolund, P. and Hunhammar, S. (1999) Ecosystem Services in Urban Areas. Ecological Economics, 29, 293-301. https://doi.org/10.1016/S0921-8009(99)00013-0

[15] Tzoulas, K., Korpela, K., Venn, S., Yli-Pelkonen, V., Kaźmierczak, A., Niemela, J. and James, P. (2007) Promoting Ecosystem and Human Health in Urban Areas Using Green Infrastructure: A Literature Review. Landscape and Urban Planning, 81, 167-178. https://doi.org/10.1016/j.landurbplan.2007.02.001

[16] Jenkins, H. (2015) Cultura da convergência Aleph.

[17] Rose, N. (1999) Powers of Freedom: Reframing Political Thought. Cambridge University Press, Cambridge.

[18] Santos, R., Teixeira, M.M., Teixeira, C.A.C., Trinta, F.A.M. and Farias, P.P.M. (2009) Conceitos de Mineração de Dados na Web XV Simpósio Brasileiro de Sistemas Multimídia e Web, VI Simpósio Brasileiro de Sistemas Colaborativos-Anais. 81-124.

[19] Han, J.W., Kamber, M. and Pei, J. (2012) Classification: Basic Concepts. In: Han, J.W., Kamber, M. and Pei, J., Eds., Data Mining. Concepts and Techniques, Morgan Kaufmann, Burlington, 327-391.

[20] Anthopoulos, L.G. (2017) Smart Government: A New Adjective to Government Transformation or a Trick? In: Understanding Smart Cities: A Tool for Smart Government or an Industrial Trick, Springer, Cham, 263-293. https://doi.org/10.1007/978-3-319-57015-0_6

[21] Forns-Samso, F., Laine, T., Oy, G., Sousa, F., Mendes, J.M. and Meireles, A.R. (2014) Acilities M. Building Information Modeling. 54.

[22] Zhuhadar, L., Thrasher, E., Marklin, S. and de Pablos, P.O. (2017) The Next Wave of Innovation-Review of Smart Cities Intelligent Operation Systems. Computers in Human Behavior, 66, 273-281. https://doi.org/10.1016/j.chb.2016.09.030

[23] Misuraca, G., Broster, D. and Centeno, C. (2012) Digital Europe 2030: Designing Scenarios for ICT in Future Governance and Policy Making. Government Information Quarterly, 29, S121-S131. https://doi.org/10.1016/j.giq.2011.08.006

[24] M'barek, B.E.N., Jeddi, A. and Achouri, M.A. (2015) Impact of Social Media on the Behavior of Tunisian Voters: 2014 Elections. British Journal of Marketing Studies, 3, 32-44.

[25] Shiramatsu, S., Ozono, T. and Shintani, T. (2015) SOCIA: Linked Open Data of Context behind Local Concerns for Supporting Public Participation. International Journal of Advanced Computer Science and Applications, 6, 268-277. https://doi.org/10.14569/IJACSA.2015.060238

[26] Han, J., Pei, J. and Kamber, M. (2011) Data Mining: Concepts and Techniques. Elsevier, New York.

[27] Salim, F. and Haque, U. (2015) Urban Computing in the Wild: A Survey on Large Scale Participation and Citizen Engagement with Ubiquitous Computing, Cyber Physical Systems, and Internet of Things. International Journal of Human-Computer Studies, 81, 31-48. https://doi.org/10.1016/j.ijhcs.2015.03.003 
[28] Al Nuaimi, E., Al Neyadi, H., Mohamed, N. and Al-Jaroodi, J. (2015) Applications of Big Data to Smart Cities. Journal of Internet Services and Applications, 6, 25. https://doi.org/10.1186/s13174-015-0041-5

[29] Netousek, T., Gugumuk, H. and Beleznai, C. (2014) Real-Time Multimedia Policy Analysis of Using Video and Audio Recognition from Radio, TV, and User-Generated Content. In: Handbook of Research on Advanced ICT Integration for Governance and Policy Modeling, IGI Global, Hershey, 248-271. https://doi.org/10.4018/978-1-4666-6236-0.ch013

[30] Rojas, L. and Henao, D. (2017) Participatión Ciudadana y Narrativas Transmedia en la Comuna 13 de Medellín-Colombia. In: Cabral, Bolaño, Araujo, Andacht, Paulino, Eds., New Concepts and Territories in Latin America, Página, 559-580.

[31] Nelson, D. (2013) Social Media Enactment Study for the District of North Vancouver.

[32] Messina, M.J. (2012) Crowdsourcing for Transit-Oriented Planning Projects: A Case Study of "Interactive Somerville". Doctoral Dissertation, Tufts University, Medford.

[33] Mehta, S.M. (2011) Mobile 311; A Framework for 311 Services with Mobile Technology. Doctoral Dissertation.

[34] Furtado, V., Caminha, C., Ayres, L. and Santos, H. (2012) Open Government and Citizen Participation in Law Enforcement via Crowd Mapping. IEEE Intelligent Systems, 27, 63-69. https://doi.org/10.1109/MIS.2012.80

[35] Aladalah, M., Cheung, Y. and Lee, V.C. (2016) Delivering Public Value: Synergistic Integration via Gov 2.0. 49 th Hawaii International Conference on System Sciences, Koloa, 5-8 January 2016, 3000-3009. https://doi.org/10.1109/HICSS.2016.376

[36] Schneider, D., de Souza, J. and Lucas, E.M. (2014) Towards a Typology of Social News Apps from a Crowd Computing Perspective. IEEE International Conference on Systems, Man and Cybernetics, San Diego, 5-8 October 2014, 1134-1140. https://doi.org/10.1109/SMC.2014.6974066

[37] Rey, M.C.N. and García, X.L. (2016) Online Media in a Context of Proximity in Galicia and Portugal and Its Presence on the Social Networks. 11 th Iberian Conference on Information Systems and Technologies, Gran Canaria, 15-18 June 2016, 1-6.

[38] Sibande, R. and Thinyane, H. (2016) A Mobile Based Technology Platform for Citizen Engagement in Malawi. IST Africa Week Conference, 1-10.

[39] Urban Systems. http://www.urbansystems.com.br/

[40] Gomyde, A. (2017) Cidades inteligentes e humanas.

[41] Afonso, R.A., Silva, W.D., Tomas, G.H.R.P., Gama, K., Oliveira, A., Alvaro, A. and Garcia, V.C. (2013) Br-SCMM: Modelo Brasileiro de Maturidade para Cidades Inteligentes Simpósio Brasileiro De Sistemas De Informação.

[42] Lévy, P. (2007) Inteligência coletiva (A) Edições Loyola.

[43] Hutchins, E. (2000) Distributed Cognition. International Encyclopedia of the Social and Behavioral Sciences, Elsevier Science, New York.

[44] Norman, D.A. (1991) Cognitive Artifacts. In: Carroll, J.M., Ed., Cambridge Series on Human-Computer Interaction, No. 4. Designing Interaction: Psychology at the Human-Computer Interface, Cambridge University Press, New York, 17-38. 